\title{
Development of a new generation of optical slope measuring profiler
}

\author{
Valeriy V. Yashchuk ${ }^{\mathrm{a},}$, Peter Z. Takacs ${ }^{\mathrm{b}}$, Wayne R. McKinney ${ }^{\mathrm{a}}$, Lahsen Assoufid ${ }^{\mathrm{c}}$, \\ Frank Siewert $^{\mathrm{d}}$ and Thomas Zeschke ${ }^{\mathrm{d}}$ \\ aAdvanced Light Source, Lawrence Berkeley National Laboratory, Berkeley, CA 94720, \\ USA \\ ${ }^{\mathrm{b}}$ Brookhaven National Laboratory, Upton, NY 11973, USA \\ ${ }^{c} \mathrm{X}$-ray Science Division, Argonne National Laboratory, Argonne, IL 60439, USA \\ ${ }^{\mathrm{d}}$ Helmholtz Zentrum Berlin für Materialien und Energie, Elektronenspeicherring BESSY- \\ II, Albert-Einstein-Str. 15, 12489 Berlin, Germany \\ * E-mail: vvyashchuk@lbl.gov; Phone: +1-510-495-2592; Fax: +1-510-486-7696
}

\begin{abstract}
A collaboration, including all DOE synchrotron labs, industrial vendors of $x$-ray optics, and with active participation of the HBZ-BESSY-II optics group has been established to work together on a new slope measuring profiler - the optical slope measuring system (OSMS). The slope measurement accuracy of the instrument is expected to be $<50$ nrad for the current and future metrology of $x$-ray optics for the next generation of light sources. The goals were to solidify a design that meets the needs of mirror specifications and also be affordable; and to create a common specification for fabrication of a multi-functional translation/scanning (MFTS) system for the OSMS. This was accomplished by two collaborative meetings at the ALS (March 26, 2010) and at the APS (May 6, 2010).
\end{abstract}

Keywords: x-ray optics, surface metrology, surface slope measurement, long trace profiler, LTP, NOM, surface profilometer, autocollimator, pentaprism

\section{Introduction}

The most advanced light sources, such as the SLAC Free Electron Laser (FEL), LCLS, National Synchrotron Light Source II (NSLS-II), the European X-FEL, and the Next Generation Light Source (NGLS) focus the need for higher performing X-ray optics with unprecedented tolerances [1-3]. The beamlines for LCLS, NSLS-II, and planned upgrade to APS, capable of providing nano-focusing with stable parameters of high brightness, coherent $\mathrm{x}$-ray beams, require optics of a slope error of $<0.1 \mu \mathrm{rad}$ (rms). The development of fabrication technologies is impossible without development of metrology that is necessary for production of such optics [4].

The best profilers, such as the NOM at Helmholtz Zentrum Berlin (HZB)/BESSY-II [5-8] and at the Diamond Light Source [9], the ESAD instrument at the PTB [10-12], DLTP at the ALS [13], and upgraded LTPs at the ALS [14-15] and SPRING-8 [16], come close to the requirements. Most are based on a careful optomechanical design, and operate in exceptional environmental conditions.

Currently, performance at $0.1 \mu \mathrm{rad}$ is possible only with flat and slightly curved optics. For curved optics, the accuracy limit is $\sim 0.25 \mu \mathrm{rad}$. Limitations are instrumental systematic errors and temporal instabilities. Recently, methods for calibration of systematic errors [17,18], and suppression of errors due to set-up drifts [19] have appeared. Attaining these advantages requires reconsideration of a new instrument for the required high precision surface slope measurement. 
Here, we review the results of a broad collaboration, including DOE synchrotron labs, vendors of x-ray optics with active participation of the HBZ/BESSY-II optics group, on the development of a new slope measuring profiler - the Optical Slope Measuring System (OSMS) - capable of absolute surface slope metrology of $<50 \mathrm{nrad}$.

\section{OSMS Working Meetings}

Scientists from DOE labs initiated the discussion with general ideas. The first LTPs in 1988 [20-21] until present were reviewed by P.Z.T. and V.V.Y. The first significant improvement of the LTP was addition of a reference arm [22]. With a Dove prism, and a reference mirror fixed on the optical table, the reference arm monitors the combined error due to carriage wobbling and beam pointing instability. The LTP schematic improvement has resulted in $\sim 1 \mu \mathrm{rad}$ (rms) accuracy.

The reference optical path highlighted error due to air convection. Together with temporal instability of the instrument, and systematic errors due to inhomogeneity of optical materials of the LTP sensor, these factors limit the performance of surface slope metrology. The problems related to the air convection noise and drift error were partially solved by using an enclosure and stabilization of lab environmental conditions. The room-in-a-room approach of many provides an exceptional environment. However, the equilibrium time may be $\sim 1$ day that significantly increases the time required for a high presicion measurement.

Partially, the problem of instrumental drifts can be overcome by the method suggested in Ref. [19]. The method is based on multiple measurements with optimal reversal of the scan direction and flipping the orientation of the SUT. Practically, in order to minimize the drift error, from 8 to 16 scans are needed.

More improvement of the ALS LTP-II performance was obtained with a new 2D detector and a motion and data system based on LabView ${ }^{\mathrm{TM}}$ [14]. With a 2D detector, averaging of measurements with different tilts of the surface under test (SUT) reduces error from the inhomogeneity of the material of the beam splitter and Fourier transform lens. Moreover, the systematic error due to the pixel-to-pixel variation of the photo-response is significantly suppressed. As a result, performance of the ALS LTP-II reached $0.25 \mu \mathrm{rad}$ (rms), cross-checked by measurements with the NOM [4]. The OSMS should provide automatic change of the roll and pitch angles of the SUT.

The best performing profilers like HBZ/BESSY-II NOM [5-8] have a movable mirror based pentaprism [19-20,22-23] and an autocollimator (AC) as a sensor [5,24]. Accuracy of the instruments is based on high precision calibration of the ACs for small apertures of 2.5 - $5 \mathrm{~mm}[25-26]$.

In 2008, a profiler based on a pentaprism and an AC, the DLTP, a low-budget instrument for development, was built at the ALS [13]. Developments with the DLTP [19,28-30] are included in the ALS LTP-II [14] and DLTP [13]. The OSMS motion and data system should allow different types of SUT and reference sensors. For measurements with different sensors, the system should have both an in-flight and start-stop modes of operation.

Vendors of x-ray optics provided crucial input. Slow measurement rates are a major difficulty. Thus, for the ALS LTP-II [14-15] one point requires 12 sec. During this time, 
the translation system sets the position ( $8 \mathrm{sec})$, waits for settling $(\sim 3 \mathrm{sec})$, and collects 10 data frames $(\sim 1 \mathrm{sec})$. For a $400 \mathrm{~mm}$ mirror, 8 scans take $\sim 10$ hours leading to large sensitivity to temporal instability (drift).

Such slow metrology is not acceptable for vendors of x-ray optics. Therefore, the OSMS system must provide metrology of $\sim 0.1 \mu \mathrm{rad}$ with an improved measurement rate via an in-flight mode. In this respect, the OSMS translation system should allow a large field of view sensor (e.g., interferometer) with a significantly increased total mass ( $<50 \mathrm{~kg})$.

\section{OSMS Multi-Functional Translation/Scanning (MFTS) System}

The major feature of the OSMS MFTS system is modularity consisting of four parts: Xtranslational system; Y-translation system; rotation and flipping stage; and alignment stage - Fig. 1.

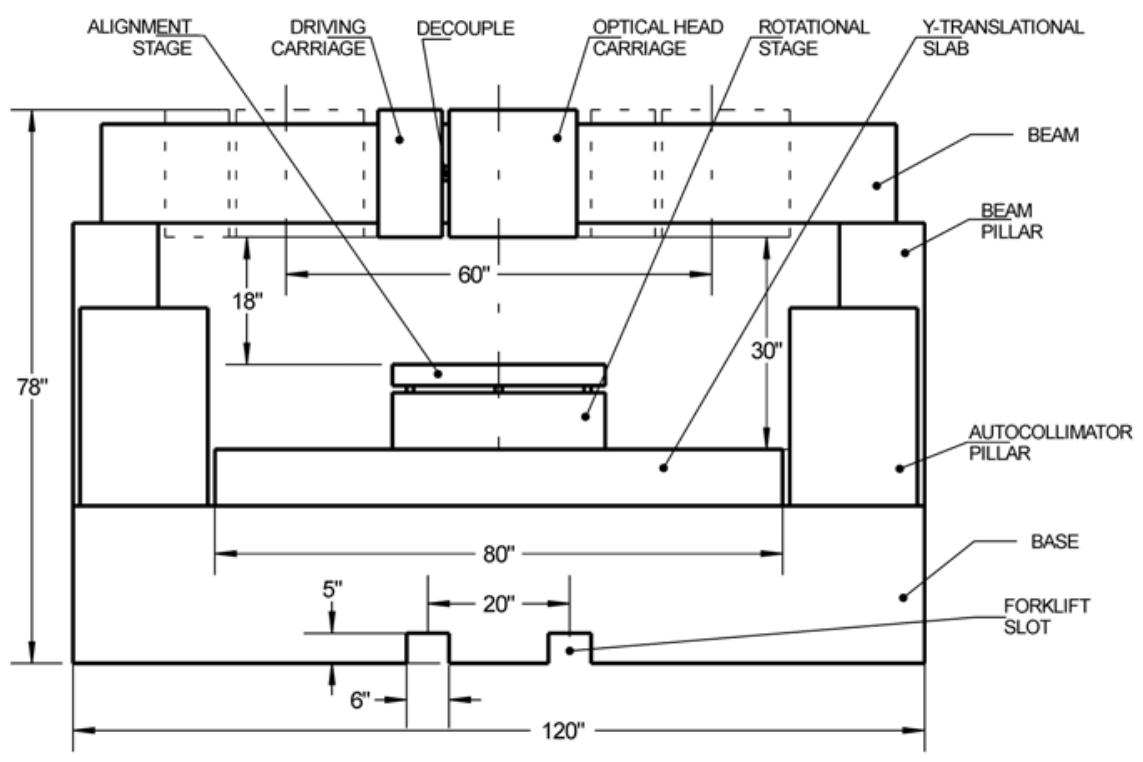

Figure 1: Schematic sketch of side view of the Multi-functional Translation System of a new generation Optical Slope Measuring System.

Like a NOM, the OSMS MFTS provides 1D and 2D metrology of a SUT. Scanning of $\sim 1.5$ meters in the tangential (X) direction is provided by the OSMS optical sensor on a carriage suspended with air-bearings on a directing beam. For 2D measurements, \pm 6 -inch displacement of a SUT in the sagittal (Y) direction is provided with a Y-translational system, including an air suspended slab on a massive base.

The OSMS MFTS includes integrated rotation/flipping and alignment stages. Yaw rotation and $180^{\circ}$ flipping of the SUT can be automated, allowing suppression of the drift error [19]. The stage provides manual alignment of roll and pitch angles and automatic roll angle adjustment. By averaging measurements at different orientations of the SUT with respect to the sensor, errors related to the sensor are lowered [13-14,25].

Modularity provides for upgrade of less expensive systems to a complete instrument. Participating laboratories can contribute to the development of the optical sensor system and the data acquisition software, without duplication of effort. 


\section{Conclusion}

We have reviewed our collaboration on development of a new generation slope measuring profiler, capable of surface slope metrology with $<50$ nrad accuracy. Economies of scale would be advantageous to all concerned. We coordinate possible procurement at all facilities.

\section{Acknowledgements}

The authors wish to thank our collaborators for productive discussions, and to acknowledge the ALS and APS staffs.

The ALS is supported by the Director, Office of Science, Office of BES, MSD, of the U.S. DOE under Contract No. DE-AC02-05CH11231 at LBNL. Research at BNL is sponsored by the U.S. DOE under Contract No. DE-AC02-98CH10886. Work performed at ANL was supported by the U.S. DOE, Office of Science, Office of BES, under Contract No. DE-AC02-o6CH11357.

\section{References}

[1] L. Assoufid, O. Hignette, M. Howells, S. Irick, H. Lammert, and P. Takacs, Nucl. Inst. Meth. A 467-468, Part 1 (2001) 267-270.

[2] P.Z. Takacs, X-ray optics metrology, in: M. Bass (Ed.), Handbook of Optics, third ed., vol. V, chapter 46, McGraw-Hill, New York, 2009.

[3] L. Samoylova, H. Sinn, F. Siewert, H. Mimura, K. Yamauchi, and T. Tschentscher, Proc. SPIE 7360 (2009) 73600E-9.

[4] H. Thiess, H. Lasser, and F. Siewert, Nucl. Inst. Meth. A 616(2-3) (2010) 157-161.

[5] E. Debler, K. Zander, PTB Mitteilungen Forschen+Prüfen, Amts und Mitteilungsblatt der Physikalisch Technischen Bundesanstalt, Braunschweig und Berlin, 1979, pp. 339349.

[6] F. Siewert, T. Noll, T. Schlegel, T. Zeschke, and H. Lammert, AIP Conf. Proc. 705 (2004) 847-850.

[7] H. Lammert, T. Noll, T. Schlegel, F. Siewert, and T. Zeschke, Patent \#DE 10303 659, Germany (2005).

[8] F. Siewert, H. Lammert and T. Zeschke, The nanometer optical component measuring machine, Modern Developments in X-ray and Neutron Optics, Springer (2008).

[9] S.G. Alcock, K.J.S. Sawhney, S. Scott, U. Pedersen, R. Walton, F. Siewert, T.

Zeschke, F. Senf, T. Noll, H. Lammert, Nucl. Inst. Meth. A 616(2-3) (2010) 224-228.

[10] R. D. Geckeler, and I. Weingaertner, Proc. SPIE 4779 (2002) 1-12.

[11] R. D. Geckeler, Proc. SPIE 6293 (2006) 62930O/1-12.

[12] R. D. Geckeler, Proc. SPIE 6317 (2006) 63171H/1-13.

[13] V. V. Yashchuk, S. Barber, E. E. Domning, J. L. Kirschman, G. Y. Morrison, B. V. Smith, F. Siewert, T. Zeschke, R. Geckeler, A. Just, Nucl. Inst. Meth. A 616(2-3) (2010) 212-223. 
[14] J. L. Kirschman, E. E. Domning, W. R. McKinney, G. Y. Morrison, B. V. Smith, and V. V. Yashchuk, Proc. SPIE 7077 (2008) 70770A/1-12.

[15] W. R. McKinney, M. Anders, S. K. Barber, E. E. Domning, Y. Lou, G. Y. Morrison, F. Salmassi et al., Proc. SPIE 7801 (2010) 780106/1-12.

[16] Y. Senba, H. Kishimoto, H. Ohashi, H. Yumoto, T. Zeschke, F. Siewert, S. Goto et al., Nucl. Inst. Meth. A 616(2-3) (2010) 237-240.

[17] V. V. Yashchuk, W. R. McKinney, T. Warwick, T. Noll, F. Siewert, T. Zeschke, and R. D. Geckeler, Proc. SPIE 6704 (2007) 67040A/1-12.

[18] F. Siewert, J. Buchheim, T. Zeschke, Nucl. Inst. Meth. A 616(2-3) (2010) 119-127.

[18] V. V. Yashchuk, Rev. Sci. Inst. 80(11) (2009) 115101.

[19] P. Z. Takacs, S. Qian, and J. Colbert, Proc. SPIE 749 (1987) 59-64.

[20] P. Z. Takacs, and S. Qian, "Surface Profiling Interferometer" Associated Universities, Patent \#4,884,697, USA (1989).

[21] S. C. Irick, W. R. McKinney, D. L. J. Lunt, and P. Z. Takacs, Rev. Sci. Inst. 63 (1992) 1436-1438.

[22] S. Qian, W. Jark, and P. Z. Takacs, Rev. Sci. Inst. 66(3) (1995) 2562-2569.

[23] K. von Bieren, Laser Diagnostics 343 (1982) 101-108.

[24] R. D. Geckeler, A. Just, M. Krause, and V. V. Yashchuk, Nucl. Inst. Meth. A 616(23) (2010) 140-146.

[25] R. D. Geckeler, I. Weingaertner, A. Just, and R. Probst, Proc. SPIE 4401 (2001) 184-195.

[26] A. Just, M. Krause, R. Probst, R. Wittekopf, Metrologia 40 (2003) 288.

[27] V. V. Yashchuk, Proc. SPIE 6317 (2006) 63170A/1-12.

[28] J.L. Kirschman, B.V. Smith, E.E. Domning, S.C. Irick, A.A. MacDowell, W.R. McKinney, G.Y. Morrison, B.V. Smith, T. Warwick, V.V. Yashchuk,, Proc. SPIE 6704 (2007) 67040J/1-11.

[29] J. L. Kirschman, E. E. Domning, G. Y. Morrison, B. V. Smith, V. V. Yashchuk, Proc. SPIE 6704 (2007) 670409/1-12. 